\title{
Lamprosoma W. Kirby (Coleoptera, Chrysomelidae): descrição de nova espécie, redescrições e chave para algumas espécies sul americanas ${ }^{1}$
}

\author{
Marcelo Galeazzi Caxambú ${ }^{2} \&$ Lúcia Massutti de Almeida ${ }^{2}$
}

1 Contribuição número 1355 do Departamento de Zoologia, Universidade Federal do Paraná.

${ }^{2}$ Laboratório de Sistemática e Bioecologia de Coleoptera, Departamento de Zoologia, Universidade Federal do Paraná. Caixa Postal 19020, 81531-980 Curitiba, Paraná, Brasil. E-mail: lalmeida@ufpr.br. Bolsista do CNPq.

\begin{abstract}
Lamprosoma W. Kirby (Coleoptera, Chrysomelidae): description of a new species, redescriptions and key to some South American species. Lamprosoma alacre sp. nov. from Mato Grosso is described and illustrated. The genus Lamprosoma is redescribed and illustrations of characters are provided. The following south american species are redescribed: $L$. amethystinum Perty, 1832, L. azureum Germar, 1824, L. bicolor W. Kirby, 1818, $L$. chrysopygium Germar, 1824, L. corruscum Guérin-Méneville, 1844, L. podtiaguini Monrós, 1947 and L. triste GuérinMéneville, 1844.
\end{abstract}

KEY WORDS. Chrysomelidae, descriptions, identification key, Lamprosoma, taxonomy.

O gênero Lamprosoma foi estabelecido por KIRBY (1818), para algumas espécies anteriormente descritas em Eumolpus Weber, 1801 e Chrysomela Linnaeus, 1758. Germar (1824) descreveu quatro novas espécies brasileiras de Lamprosoma: L. auricharorum, L. festivum, L. chrysopygium e L. azureum.

LACORDAIRE (1848) indica na quinta tribo "Clythrides" (Clythrinae), uma quarta seção denominada "Lamprosomidées" (Lamprosomideae). Define esse grupo com as seguintes características: Corpo pequeno, hemisférico, oval ou oblongo, geralmente muito convexo, glabro, quase sempre plano ventralmente e sem pigídeo distinto. Antenas recolhidas em repouso sobre ranhuras protorácicas; prosterno distinto, apoiado atrás sobre o mesosterno; epimeros metatorácicos desenvolvidos anteriormente em forma de triângulo curvilíneo na frente, terminado posteriormente em ponta aguda; pernas de mesmo tamanho, contráteis; garras de formas variáveis.

Monrós (1947) foi quem mais contribuiu para o conhecimento do gênero, descrevendo dez novas espécies de Lamprosoma neotropicais, três brasileiras. Em 1956 descreveu mais algumas espécies e apresentou chave de identificação.

São indicadas para Lamprosoma 128 espécies neotropicais, sendo 54 brasileiras (Monrós 1960).

Ao estudar as espécies de Lamprosoma solicitadas às coleções nacionais, foram identificadas apenas as oito espécies aqui tratadas.

As espécies do gênero alimentam-se principalmente de plantas das famílias Combretaceae, Myrtaceae, Bombacaceae, Mimosaceae e Melastomataceae, podendo ser utilizadas no controle biológico das mesmas (Jolivet 1978, CAXAmbú \& Almeida 1999).
O último trabalho sobre o gênero foi realizado por MonRós (1956) e as descrições originais contemplam apenas a morfologia externa, baseando-se quase que exclusivamente na coloração.

\section{MATERIAL E MÉTODOS}

A metodologia adotada para as descrições é basicamente aquela citada em CaXAmbú \& AlmeIDA (1999). Com relação à terminologia, seguiu-se Monrós (1956).

O material estudado, além daquele da Coleção de Entomologia Pe. J.S. Moure, Universidade Federal do Paraná, Curitiba, Paraná (DZUP) foi cedido por empréstimo pelas seguintes instituições: Museu do Capão da Imbuia, Curitiba, Paraná (MHNCI); Museu Nacional, Universidade Federal do Rio de Janeiro, Rio de Janeiro, Rio de Janeiro (MNRJ); Museu de Zoologia, Universidade de São Paulo, São Paulo, São Paulo (MZSP); Museu de Ciências Naturais, Fundação Zoobotânica do Rio Grande do Sul, Porto Alegre, Rio Grande do Sul (MCNZ).

O material-tipo das espécies já descritas foi solicitado, porém em função da medida provisória $n^{\circ} 2186-14 / 2001$, os curadores dos museus internacionais se recusaram a enviá-lo. O material-tipo de Lamprosoma azureum e Lamprosoma chrysopygium, ambas de Germar não foram encontrados no Zoologisches Museum der Humboldt Universität, Alemanha (Pe. J. S. Moure, comunicação pessoal). O material-tipo e o parátipo de Lamprosoma alacre sp. nov., foi depositado na Coleção de Entomologia Pe. J.S. Moure. 


\section{Lamprosoma W. Kirby, 1818}

Lamprosoma W. Kirby, 1818: 445; Chevrolat, 1842: 277; Lacordaire, 1848: 574; Chapuis, 1874: 216; Jacoby, 1881:90; 1908: 281; Achard, 1914: 5; Blackwelder, 1946: 650; Chûjô, 1953: 239; Monrós, 1956: 59; 1960: 9; Caxambú \& Almeida, 1999: 244.

Forma oblonga, com pronoto largo na base, coloração metálica, às vezes multicoloridos. Cabeça não visível dorsalmente, olhos pouco chanfrados, antenas robustas, não atingindo a base do protórax, com 11 artículos, escapo longo, cada artículo com duas ou três cerdas rígidas, os seis últimos alargados e serrados, em repouso alojadas no prosterno; clípeo escavado, semicircular com ângulos laterais salientes, às vezes mais ou menos prolongados; labro pequeno, transversal, borda anterior vertical ou subemarginada; mandíbulas robustas, assimétricas. Pronoto com a base larga e impressão basal a cada lado. Escutelo reduzido. Prosterno sub-retangular, mais ou menos plano. Élitros com base sinuosa, convexos, com dez estrias formadas por fileiras de pontos, ordenadas longitudinalmente, arredondados no ápice e com úmeros salientes. Pernas robustas, deprimidas lateralmente; tíbias em triângulo alongado, escavadas para a recepção dos tarsômeros, os três primeiros bilobados, garras apendiculadas e opostas em ângulo de $180^{\circ}$. Abdome com cinco esternos visíveis, o primeiro com depressão para encaixe dos fêmures posteriores e o último serrilhado no ápice. Genitália do macho com padrão Chrysomeloidea, com parâmeros fundidos e ápice inclinado.

Discussão. Segundo MonRós (1956), o gênero Lamprosoma é muito próximo de outros dois gêneros, Dorisina Monrós e Lychnophaes Lacordaire, todos de distribuição Neotropical. Lamprosoma diferencia-se deles por apresentar as garras apendiculadas e em ângulo de $180^{\circ}$; em Dorisina e Lychnophaes as garras são simples e divergentes em ângulo mais ou menos obtuso; o bordo ocular interno é anguloso em Dorisina enquanto que nos outros dois gêneros o bordo é arredondado. Ao estabelecer o gênero Dorisina para incluir Lamprosoma pusilla Jacoby, Monrós (1956) salienta que todas as espécies de tamanho reduzido da América Central deveriam ser revisadas e talvez transferidas para esse gênero. Os exemplares disponíveis do gênero Dorisina que foram utilizados para comparação neste estudo, também apresentam tamanho reduzido, porém são distribuídos no sul da América do Sul.

\section{Chave para as espécies mais comuns de Lamprosoma}

1. Coloração dorsal uniforme .................................................... 2

1'. Coloração dorsal com manchas ou reflexos ...................... 4

2. Coloração dorsal azul ........................................................ 3

2 '. Coloração dorsal violeta brilhante, ventralmente variando de preto com reflexo violeta a azul violáceo; processo prosternal duas vezes mais longo que largo, subcôncavo ..........

L. amethystinum

3. Coloração azul índigo brilhante, processo prosternal duas vezes mais longo que largo; nos machos com dente nos fêmures anteriores e tíbias angulosas; processo prosternal duas vezes mais longo que largo, com base e ápice truncados L. azureum

3'. Coloração azul opaca; processo prosternal subquadrado; pernas sem dimorfismo sexual; processo prosternal subquadrado....... L. triste
4. Coloração azul violácea com manchas douradas ou verde douradas metálicas ................................................................ 5

4'. Coloração predominantemente negra ou dourada com reflexos, com manchas verde douradas ou de coloração azul ou violeta

5. Coloração azul violáceo com a margem apical dourada; labro recortado com três dentes no ápice; processo prosternal subquadrado, com ápice truncado ............ L. chrysopygium

5'. Coloração azul violáceo escuro com duas manchas láterobasais verde douradas no pronoto e uma mancha transversal na metade apical de cada élitro; processo prosternal subquadrado, lateralmente estreitado ........... L. podtiaguini

6. Coloração negra com duas faixas azuladas transversais cintilantes no pronoto e no ápice dos élitros; processo prosternal subquadrado, lateralmente pouco estreitado .......... L. alacre sp. nov.

6'. Outra combinação de cores .............................................. 7

7. Coloração negra com reflexos verde metálicos; cada élitro com mancha apical desde a metade lateral; ventralmente negros; processo prosternal lateralmente com ápice arredondado . L. corruscum

7'. Coloração dourada cúprea com reflexos verde metálicos, ventralmente violáceo; processo prosternal com ápice truncado L. bicolor

\section{Lamprosoma amethystinum Perty, 1832 Figs 1, 9-12}

Lamprosoma amethystinum Perty, 1832: 104; Lacordaire, 1848: 597; Achard, 1914: 5; Monrós, 1960: 9.

\section{Lamprosoma amethystina: Blackwelder, 1946: 650.}

Diagnose. Dorsalmente violeta brilhante e ventralmente preto com reflexos violeta a azul violáceo (Fig. 1). Protórax lobado posteriormente, uniformemente pontuado. Processo prosternal duas vezes mais longo que largo, côncavo e grossamente pontuado, com os ângulos laterais agudos e ápice truncado, de lados arredondados (Fig. 9). Quilha metasternal estreita e alongada, atingindo a metade da largura do metasterno (Fig. 10). Comprimento $6,83-8,50 \mathrm{~mm}$; largura 5,0-6,0 $\mathrm{mm}$.

Macho. Genitália (Fig. 11) com cerdas laterais desenvolvidas, curtas, subiguais, valva pequena e pontiaguda.

Fêmea. Genitália (Fig. 12) composta por espermateca simples, em forma de ferradura, bem esclerotizada, largura não uniforme, com parede muito fina. Ducto espermático muito longo, tubular, de largura quase uniforme, em formato de serpentina, esclerotizado. Coxitos de base afilada e ápice largo, mais ou menos arredondado, com cerdas longas. Estilos não aparentes.

Material Examinado. Bolívia, Santa Cruz: Província del Sara (450 m), XI/1910, J. Steinbach leg., 4552, 1 exemplar, (MZSP); BrasiL, Friedenreich leg., 9391, 1 exemplar, (MNRJ); Mato Grosso: Dourados, 29-30/XII/1975, J. Lorenson leg., 1 exemplar; Minas Gerais: Araxá, 14/XI/1965, C. Elias leg., 1 exemplar; 22/XI/1965, C.T. \& C. Elias leg., 1 exemplar; 06/XI/ 1965, C.T. \& C. Elias leg., 1 exemplar; Colinto, 14/XI/1977, J.S. Moure leg., 1 exemplar, (DZUP); São Paulo: São Paulo, XII/1927, Azevedo Marques leg., Inst. Biol. Entomologia Agrícola do Rio de Janeiro, 6.654, 1 exemplar; Angatuba, I/1922, Azevedo Marques leg., Inst. Biol. Entomologia Agrícola do Rio de Janeiro, 2.390, 1 exemplar, (MNRJ); Rio Grande do Sul: Montenegro, 3/ 

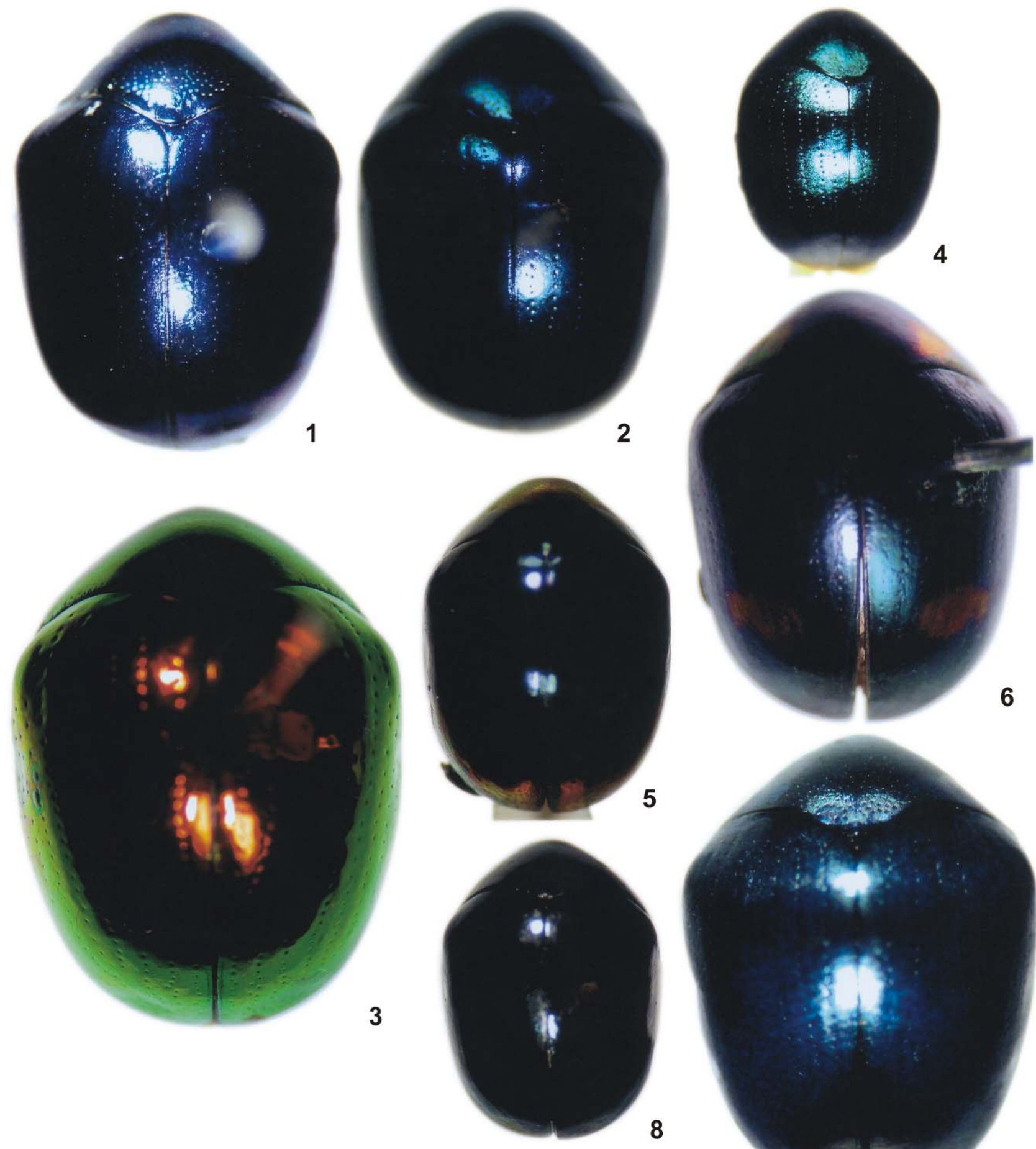

8

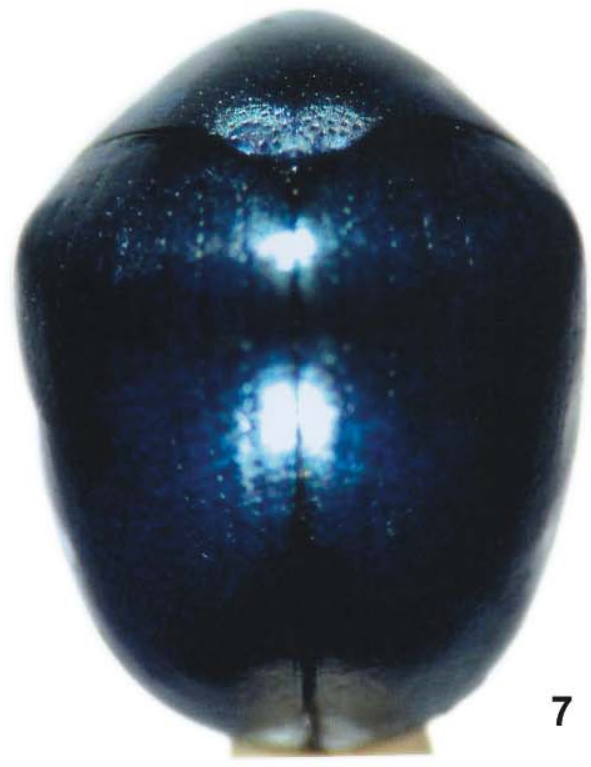

Figuras 1-8. (1) Lamprosoma amethystinum, (2) Lamprosoma azureum, (3) Lamprosoma bicolor, (4) Lamprosoma chrysopygium. (5) Lamprosoma corruscum, (6) Lamprosoma podtiaguini, (7) Lamprosoma triste, (8) Lamprosoma alacre sp. nov. 


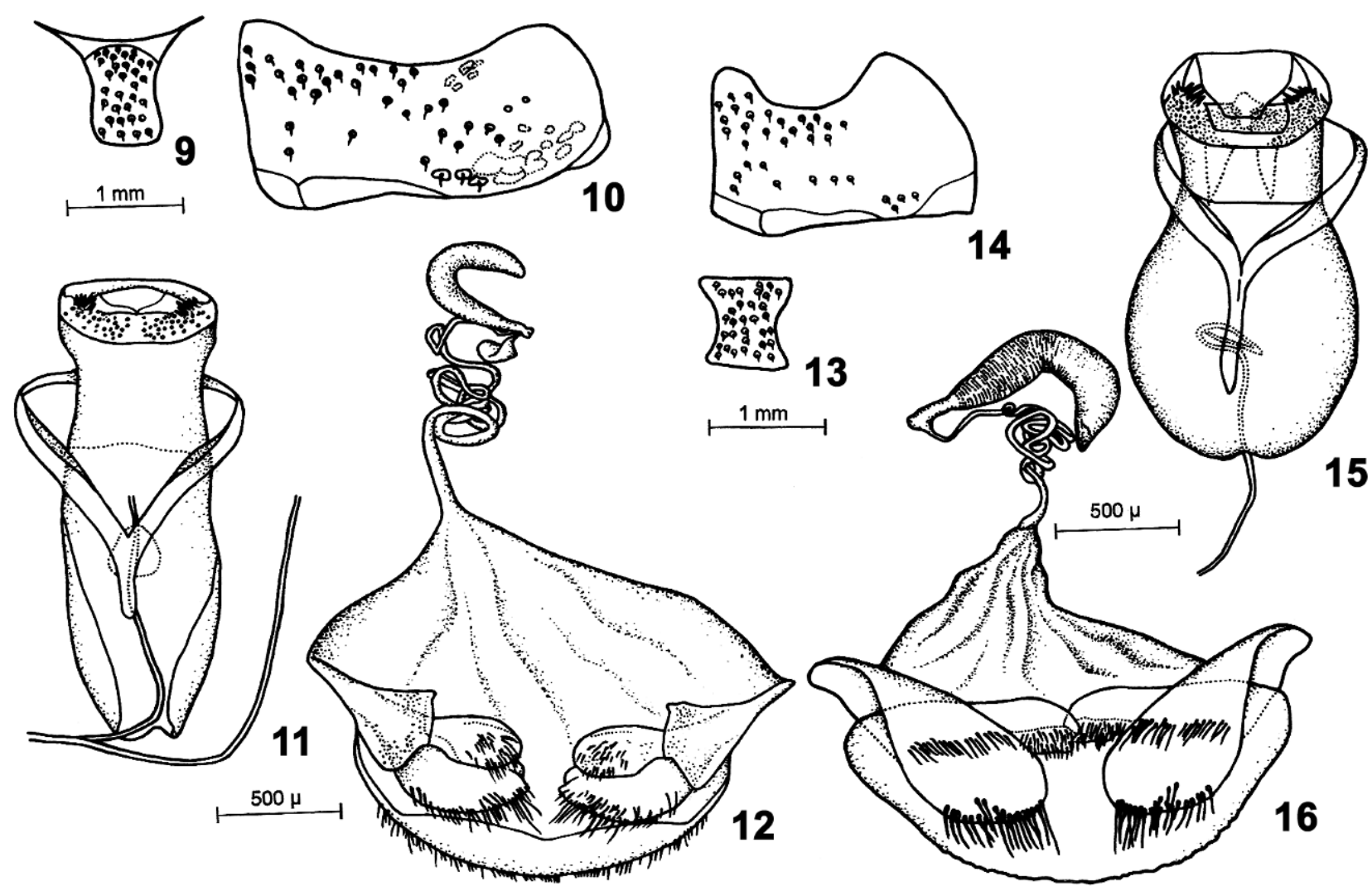

Figuras 9-16. (9-12) Lamprosoma amethystinum: (9) processo prosternal, (10) metasterno, (11) edeago, (12) genitália da fêmea; (1316) Lamprosoma azureum: (13) processo prosternal, (14) metasterno, (15) edeago, (16) genitália da fêmea.

XI/1977, H.A. Gastal, 25516, 1 exemplar; 17/XI/1977, T. Arigony, 24.926, 1 exemplar, (MCNZ).

Material-tipo. O material-tipo de Lamprosoma amethystinum Perty, 1832 encontra-se depositado no Museum Frey, Munique, Alemanha.

\section{Lamprosoma azureum Germar, 1824 Figs 2, 13-16}

Lamprosoma azureum Germar, 1824: 575; Lacordaire, 1848: 592; Achard, 1914: 6; Monrós, 1956: 62; 1960: 12; Caxambú \& Almeida, 1999: 245.

Lamprosoma azurea; Blackwelder, 1946: 651.

Diagnose. Coloração dorsal azul índigo ao azul, com reflexos esverdeados ou chumbo (Fig. 2), ventralmente uniformemente negro. Processo prosternal duas vezes mais longo que largo, lateralmente estreitado e pontuado, com base e ápice truncados (Fig. 13). Quilha metasternal estreita e alongada, atingindo cerca de dois terços da largura do metasterno (Fig. 14). Machos com fêmures anteriores obtusamente denteados e tíbias internamente angulosas.

Comprimento 6,00-7,17 mm; largura 4,33-5,33 mm.

Macho. Genitália (Fig. 15), com cerdas laterais desenvol- vidas e valva de ápice truncado.

Fêmea. Genitália (Fig. 16) composta por espermateca simples, em forma de ferradura, bem esclerotizada, largura uniforme, com parede muito fina. Ducto espermático longo, tubular, de largura quase uniforme, em formato de serpentina, esclerotizado. Coxitos de base afilada e ápice largo, mais ou menos truncado, com cerdas longas. Estilos não aparentes.

Material Examinado. BRASIL, Minas Gerais: Araxá, 10/XII/ 1965, C.T. \& C. Elias leg., 1 exemplar; 29/XI/1965, 2 exemplares; São Paulo: São José do Barreiro (Serra da Bocaina), XI/1967, Alvarenga \& Seabra leg., Ex Coleção M. Alvarenga; Paraná: Curitiba, XII/1937, 7.347, 1 exemplar (MHNCI); 14/V/1968, J.S. Moure leg., 1 exemplar; 18/XI/1968, Exc. Depto Zoologia leg., 1 exemplar; 25/X/1995, M.G. Caxambú leg., 1 exemplar; 15/X/1997, 2 exemplares; 11/XI/1997, 2 exemplares; 16/XI/ 1997, 6 exemplares; 17/XI/1997, 3 exemplares; 24/XI/1997, 2 exemplares; Paranaguá, XI/1966, S. Laroca leg., 1 exemplar; Rio Negro, XI/1925, N. Witte leg., 1 exemplar; Santa Catarina: Garuva, 05/XII/1971, J.S. Moure leg., 1 exemplar; Joinville, 19/ X/1974, Moure \& Marinoni leg., 1 exemplar (DZUP).

Material-tipo. O material-tipo de Lamprosoma azureum Germar, 1824 não foi localizado no Zoologisches Museum der Humboldt Universität, Berlim, Alemanha. 


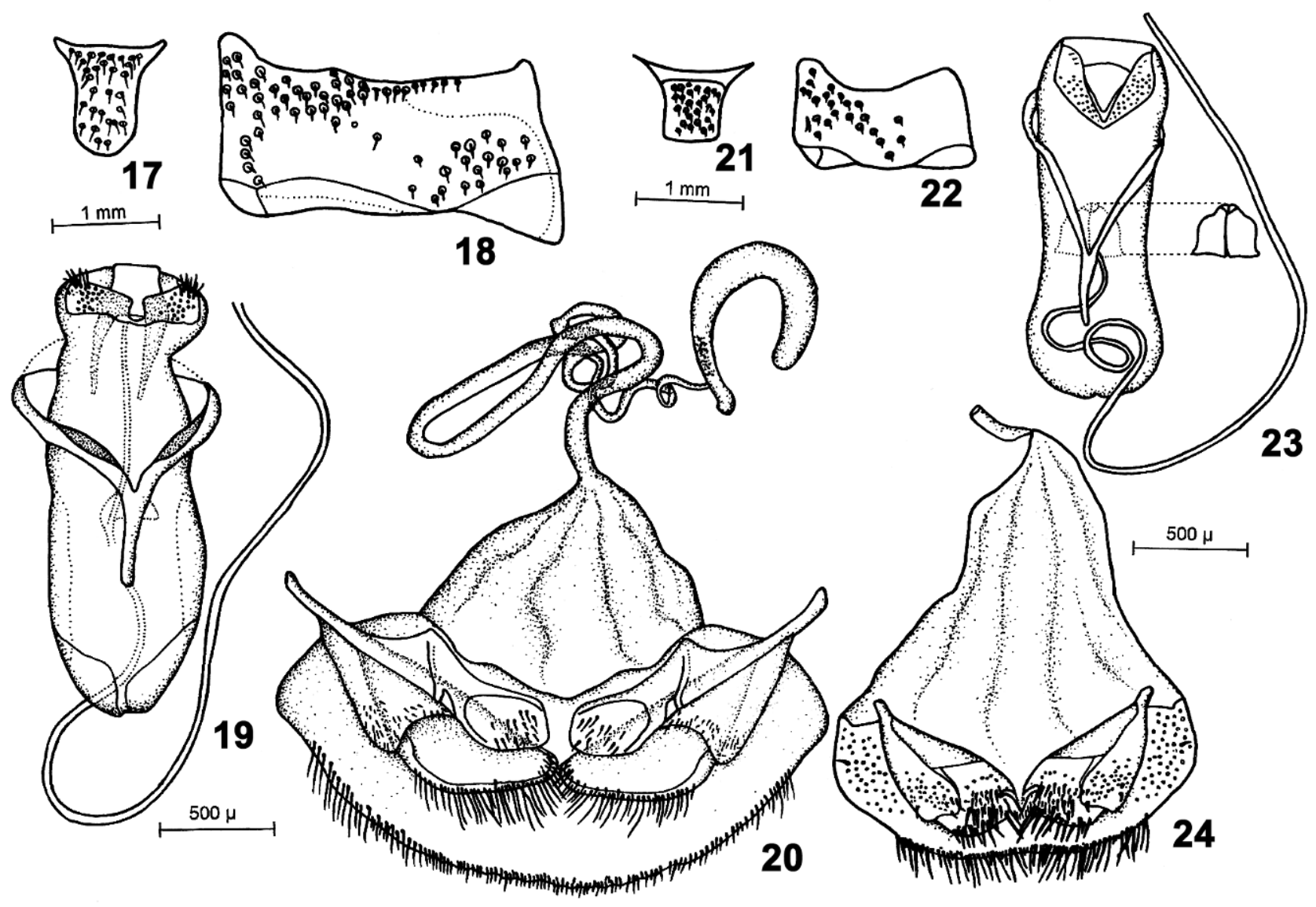

Figuras 17-24. (17-20) Lamprosoma bicolor: (17) processo prosternal, (18) metasterno, (19) edeago, (20) genitália da fêmea; (21-24) Lamprosoma chrysopygium: (21) Processo prosternal, (22) metasterno, (23) edeago, (24) genitália da fêmea.

\section{Lamprosoma bicolor W. Kirby, 1818 Figs $3,17-20$}

Lamprosoma bicolor W. Kirby, 1818: 445; Lacordaire, 1848: 616; Achard, 1914: 7; Blackwelder, 1946: 651; Guérin, 1953: 93; Costa Lima, 1955: 170; Monrós, 1960: 10.

Diagnose. Corpo dourado cúpreo com reflexos verde metálicos muito brilhantes, ventralmente violáceo (Fig. 3). Processo prosternal cerca de duas vezes mais longo que largo, com base em ângulos laterais agudos e ápice arredondado (Fig. 17). Quilha metasternal estreita e alongada, atingindo mais da metade da largura do metasterno (Fig. 18).

Comprimento 7,00-8,67 mm; largura 5,50-6,67 mm.

Macho. Genitália (Fig. 19), com cerdas laterais desenvolvidas e valva com ápice arredondado.

Fêmea. Genitália (Fig. 20) composta por espermateca simples, em forma de ferradura, bem esclerotizada, largura não uniforme, com parede muito fina. Ducto espermático robusto, muito longo, tubular, de largura variável, em formato de serpentina, esclerotizado. Coxitos de base afilada e ápice largo, mais ou menos truncado, com cerdas finas e longas. Estilos não aparentes.

Material Examinado. Brasil, Rio de Janeiro: Rio de Janeiro (Botafogo), XI/1952, L.G. Alvarenga leg., 1 exemplar; (Corcovado), XI/1958, Alvarenga \& Seabra leg., 1 exemplar; 27/X/1975, C.A. Campos Seabra leg.; (Recreio dos Bandeirantes), 23/I/1955, O. Mielke leg., 1 exemplar; VI/1915, C. Moreira leg., Laboratório de Entomologia Agrícola do Rio de Janeiro, 9.406, 1 exemplar (MNRJ); 01/XII/1966, Moure \& Seabra leg., 1 exemplar; (Represa Rio Grande), 23/XI/1960, F.M. Oliveira, 1 exemplar; 09/I/1967, 1 exemplar (DZUP); Campos (Murangaba), I/1942, M. Alvarenga leg., 452, Ex Coleção Bokermann, 1 exemplar (MZSP); Santa Catarina: Joinville, II/1921, C. Schmidt leg., 1 exemplar (MNRJ).

Material-tipo. O material-tipo de Lamprosoma bicolor W. Kirby, 1818 encontra-se depositado no Natural History Museum, Londres, Inglaterra.

Revista Brasileira de Zoologia 20 (2): 329-337, junho 2003 


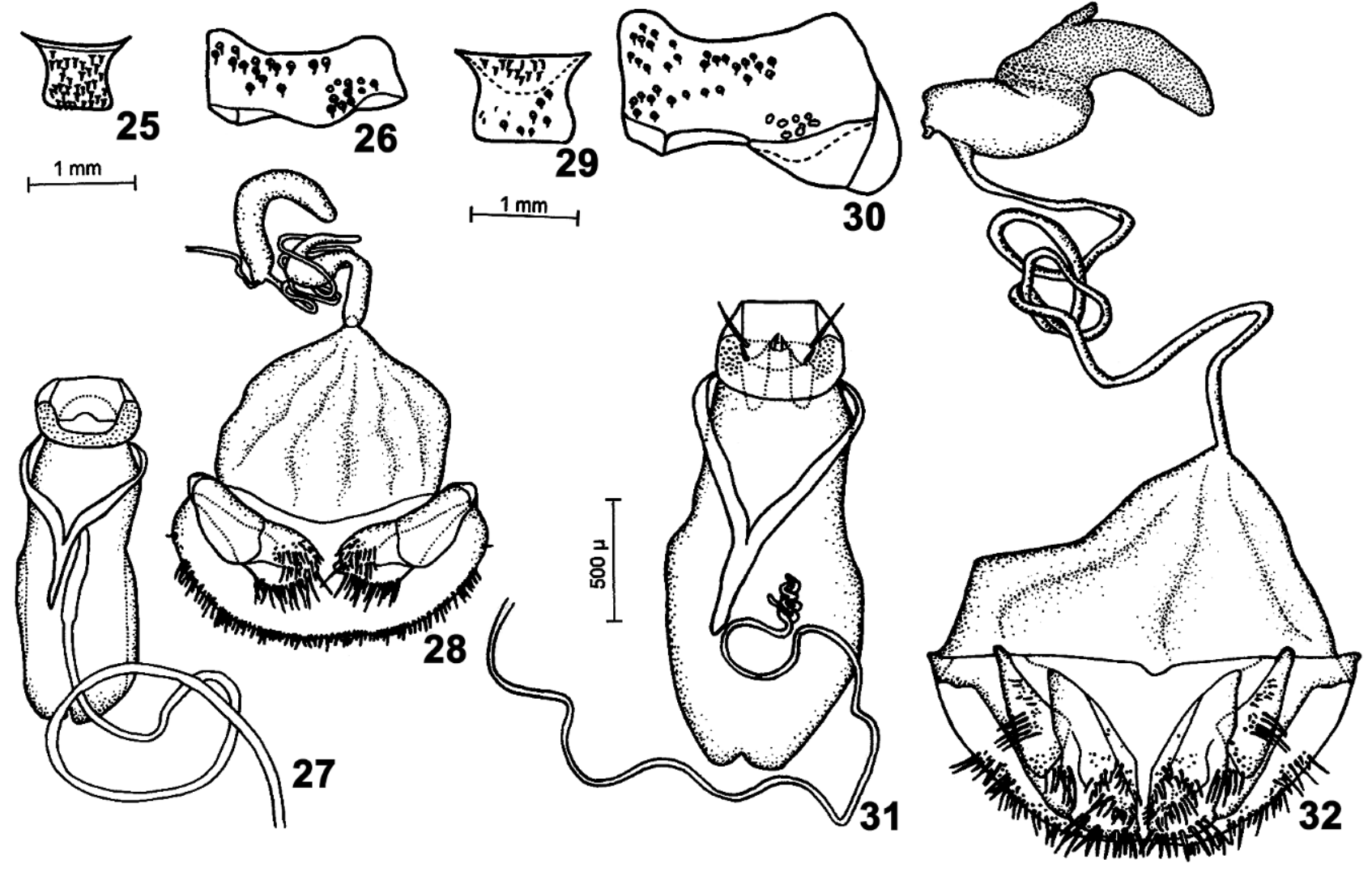

Figuras 25-32. (25-28) Lamprosoma corruscum: (25) processo prosternal, (26) metasterno, (27) edeago, (28) genitália da fêmea; (2932) Lamprosoma podtiaguini: (29) processo prosternal, (30) metasterno, (31) edeago, (32) genitália da fêmea.

\section{Lamprosoma chrysopygium Germar, 1824}

Figs 4, 21-24

Lamprosoma chrysopygium Germar, 1824: 575; Lacordaire, 1848: 585; Achard, 1914: 9; Blackwelder, 1946: 651; Monrós, 1956: 66; Monrós, 1960: 13.

Diagnose. Corpo dorsalmente violáceo esverdeado brilhante, ventralmente negro com a margem apical dourada (Fig. 4). Élitros finamente pontuados. Cabeça dourada brilhante. Labro recortado com três dentes no ápice, o central menor e em plano inferior que os laterais. Processo prosternal subquadrado, com base em ângulos laterais agudos e ápice truncado (Fig. 21). Quilha metasternal estreita e alongada, atingindo apenas o primeiro terço da largura do metasterno (Fig. 22).

Comprimento 4,5-6,0 mm; largura 3,5-4,5 mm.

Macho. Genitália (Fig. 23) com esclerito trapezoidal na região média do saco interno; valvas alongadas com ápice agudo e cerdas laterais reduzidas e delicadas.

Fêmea. Coxitos (Fig. 24) de base afilada, arredondada para o ápice com cerdas longas. Estilos pequenos, mamiliformes.

Material Examinado. BrasiL, Rio de Janeiro: Rio de Janeiro
(Corcovado), 27/X/1975, C.A. Campos Seabra leg., 2 exemplares (MNRJ); XI/1962, Alvarenga \& Seabra leg., ex Coleção Bokermann, 1 exemplar (MZSP); X/1967, ex Coleção M. Alvarenga, 2 exemplares; 06/X/1967, Moure \& Alvarenga leg., 1 exemplar (DZUP).

Material-tipo. O material-tipo de Lamprosoma chrysopygium Germar, 1824 não foi localizado no Zoologisches Museum der Humboldt Universität, Alemanha.

\section{Lamprosoma corruscum Guérin-Méneville, 1844}

Figs $5,25-28$

Lamprosoma corruscum Guérin-Méneville, 1844: 293; Lacordaire, 1848: 580; Achard, 1914: 10; Blackwelder, 1946: 651; Guérin, 1953: 93; Monrós, 1956: 66; 1960: 13.

Diagnose. Corpo brilhante, cabeça e protórax cúpreos com reflexos verde-metálicos. Élitros negros com uma mancha apical violácea extendendo-se desde a metade lateral, formando uma meia lua (Fig. 5). Face ventral negra. Processo prosternal com base em ângulos laterais agudos e ápice truncado com bordas arredondadas, lateralmente estreitado, plano (Fig. 25). 
Quilha metasternal subtriangular, atingindo pouco menos de um terço da largura do metasterno (Fig. 26).

Comprimento 3,83-5,0 $\mathrm{mm}$; largura 2,83-3,67 mm.

Macho. Genitália (Fig. 27) com espessamento do ducto ejaculatório na região média, ausência de cerdas laterais, valva subquadrada, de base e ápice reta e região mediana côncava.

Fêmea. Genitália (Fig. 28) com espermateca simples, em ferradura, bem esclerotizada, largura não uniforme, com parede muito fina. Ducto espermático robusto no seu ápice, em formato de sifão, afinando de maneira gradativa para a base formando uma serpentina, esclerotizado. Coxitos de base levemente arredondada e ápice pouco largo, mais ou menos truncado, com cerdas desenvolvidas. Estilos arredondados.

Material Examinado. BRASIL, Amazonas: Manaus, 09/XI/ 1955, Elias \& Roppa leg., 1 exemplar; 11/I/1941, Parko leg.; Pará: Óbidos, III/1922, H.C. Boy leg. (MNRJ).

Material-tipo. O material-tipo de Lamprosoma corruscum Guérin-Meneville, 1844 encontra-se no Natural History Museum, Londres, Inglaterra.

\section{Lamprosoma podtiaguini Monrós, 1947 Figs 6, 29-32}

Lamprosoma podtiaguini Monrós, 1947: 173; 1960: 14.

Diagnose. Corpo bastante convexo, azul violáceo escuro, metálico. Pronoto com duas manchas látero-basais verdedouradas. Cada élitro com uma mancha na metade apical verdedourada metálica, ovalada, transversal (Fig. 6). Processo prosternal subquadrado, lateralmente estreitado, com base de lados pontiagudos (Fig. 29). Quilha metasternal subtriangular, atingindo a metade da largura do metasterno (Fig. 30).

Comprimento 6,17 $\mathrm{mm}$; largura 4,67 $\mathrm{mm}$.

Macho. Genitália (Fig. 31). Valva com três pares de cerdas: duas pequenas centrais e de cada lado mais duas cerdas, uma longa mais apical e outra curta abaixo daquela, com aproximadamente um terço do comprimento da maior. Ducto ejaculatório muito longo e afilado.

Fêmea. Genitália (Fig. 32) composta por espermateca sigmóide, com pequena projeção no primeiro terço apical. Ducto espermático fino e alongado, esclerotizado. Coxitos de base afilada e ápice alargado, com muitas cerdas desenvolvidas. Estilos pequenos, mamiliformes.

Material Examinado. BRASIL, Santa Catarina: Seara (Nova Teutonia), I/1953, Fritz Plaumann leg., 2.733, um exemplar; M. Parko leg., um exemplar (MNRJ).

Material-tipo. O material-tipo de Lamprosoma podtiaguini Monrós, 1947 encontra-se no Smithsonian Institution, Washington, D.C., EUA.

\section{Lamprosoma triste Guérin-Méneville, 1844 Figs 7, 33-36}

Lamprosoma triste Guérin-Méneville, 1844: 294; Lacordaire, 1848: 590; Achard, 1914: 7; Monrós, 1956: 62; 1960: 12.

Lamprosoma tristis: Blackwelder, 1946: 652.

Lamprosoma subnitidum Monrós, 1947: 90; 1960: 12.

Diagnose. Corpo cinza-chumbo azulado, opaco, ventralmente negro (Fig. 7). Processo prosternal largo, com base de lados arredondados, subquadrado, lateralmente estreitado (Fig.
33). Quilha metasternal um pouco sinuosa antes da metade da largura do metasterno (Fig. 34).

Comprimento 5,83-7,17 mm; largura 4,67-5,67 mm.

Macho. Genitália (Fig. 35) com valva com cerdas subiguais, de base reta e ápice subtriangular. Ducto ejaculatório muito longo e afilado.

Fêmea. Genitália (Fig. 36) composta por espermateca simples, em forma de ferradura, bem esclerotizada, largura uniforme, com parede muito fina. Ducto espermático curto, de largura variável, em forma de ânfora, esclerotizado. Coxitos de base afilada e ápice largo, mais ou menos truncado, com cerdas longas. Estilo pouco evidente.

Material Examinado. Brasil, Distrito Federal: Brasília, 22/ X/1965, M. Becker ,27.325, 1 exemplar, (MCNZ); Espírito Santo: Jacaraipe, 11-18/II/1967, C. \& C.T. Elias leg., 1 exemplar; Baixo Guandu, 15/XII/1970, C. Elias leg., 1 exemplar (DZUP); Rio de Janeiro: Rio de Janeiro (Corcovado), IX/1958, Alvarenga \& Seabra leg., 2 exemplares; X/1958, 2 exemplares (MNRJ); VIII/ 1961, ex Coleção Bokermann, 1 exemplar (MZSP); 03/XII/1965, Moure \& Seabra leg., 1 exemplar; VIII/1966, Alvarenga e Seabra leg., Ex Coleção M. Alvarenga, 1 exemplar; XI/1966, ex coleção M. Alvarenga, 1 exemplar; XII/1966, Ex Coleção M. Alvarenga, 2 exemplares; VIII/1967, Ex Coleção M. Alvarenga, 2 exemplares; X/1967, Ex Coleção M. Alvarenga, 2 exemplares; XI/1967, ex Coleção M. Alvarenga, 1 exemplar; X/1968, Ex Coleção M. Alvarenga, 4 exemplares; IX/1969, ex Coleção M. Alvarenga, 3 exemplares (DZUP); Rio Grande do Sul: Canoas, 13/XII/1990, L. Moura, 217.389, 1 exemplar; Triunfo, 20/X/ 1977, H.Bischoff, 24694 (MCNZ).

Material-tipo. O material-tipo de Lamprosoma triste Guérin-Méneville, 1844 encontra-se depositado no Natural History Museum, Londres, Inglaterra.

\section{Lamprosoma alacre sp. nov. Figs $8,37-40$}

Diagnose. Corpo negro brilhante, com exceção da cabeça e de duas faixas azuladas cintilantes no ápice do pronoto e dos élitros (Fig. 8). Processo prosternal com base de lados angulosos, subquadrado, lateralmente pouco estreitado, e fracamente puntuado (Fig. 37). Quilha metasternal com cerca de três quartos do tamanho do metasterno (Fig. 38).

Comprimento 4,17-4,33 mm; largura 3,17-3,33 mm.

Macho. Valva da genitália (Fig. 39) com reduzidas cerdas subiguais, de base reta e ápice arredondado. Ducto ejaculatório muito longo e afilado.

Fêmea. Genitália (Fig. 40) composta por espermateca simples, com forma de ferradura, bem esclerotizada, largura não uniforme, com parede muito fina. Ducto espermático robusto no ápice, em formato de sifão, afinando de maneira gradativa para a base formando uma serpentina, esclerotizado. Coxitos de base afilada e ápice largo, mais ou menos truncado, com cerdas desenvolvidas. Estilos mamiliformes.

Material-tipo. BrasIL, Mato Grosso: Cáceres, 17-19/X/1961, F.M. Oliveira leg., o holótipo macho e mais um exemplar (DZUP).

Discussão Taxonômica. Lamprosoma alacre assemelha-se a L. corruscum pelo padrão de coloração, pois em ambas as espécies os élitros são negros e com manchas apicais. Em L. alacre as manchas são azuladas cintilantes e ocorrem também lateral- 


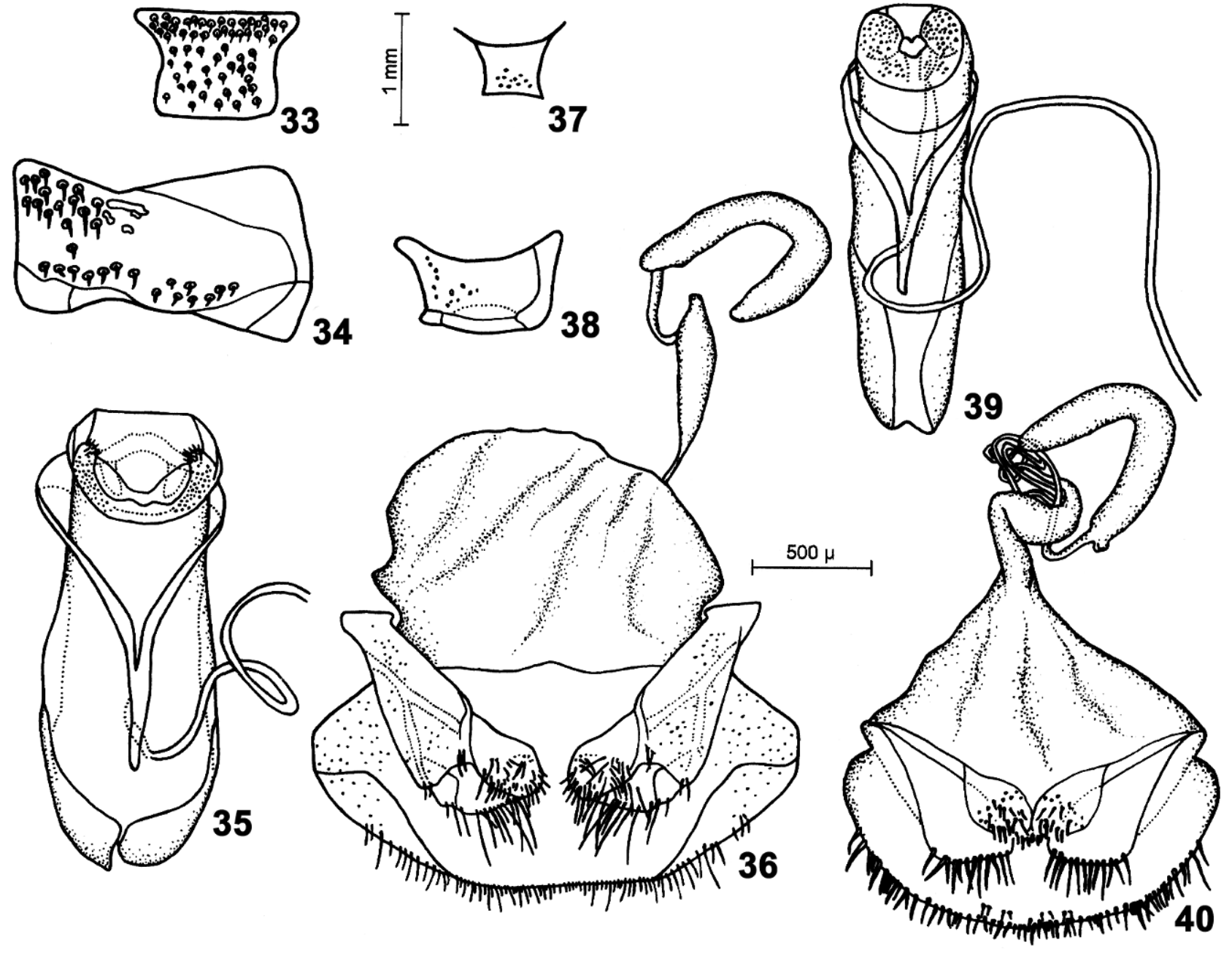

Figuras 33-40. (33-36) Lamprosoma triste: (33) processo prosternal, (34) metasterno, (35) edeago, (36) genitália da fêmea; (37-40) Lamprosoma alacre sp. nov.: (37) processo prosternal, (38) metasterno, (39) edeago, (40) genitália da fêmea.

mente no pronoto. Em L. corruscum as manchas são de coloração violácea e localizam-se apenas nos élitros. A valva da genitália do macho de $L$. alacre tem a base reta e ápice arredondado, enquanto que em L. corruscum a valva é subquadrada com ápice truncado.

Etimologia. O nome alacre em latim significa alegre, cheio de vida, jovial.

\section{AGRADECIMENTOS}

Aos curadores e/ou responsáveis pelas coleções entomológicas pelo empréstimo de material estudado neste trabalho: M.Sc. Solange Malcovsky (MHNCI); Dr. Germano Henrique Rosado-Neto (DZUP); Dra. Cleide Costa (MZSP); Dr. Miguel Angel Monné (MNRJ); Dra. Maria Helena Galileo e M.Sc. Luciano Moura (MCNZ); ao Dr. Rodney R. Cavichioli pelo auxílio nas fotografias.

Revista Brasileira de Zoologia 20 (2): 329-337, junho 2003

\section{REFERÊNCIAS BIBLIOGRÁFICAS}

ACHARD, J. 1914. In: P. WyTSMAN (Ed). Genera insectorum. Coleoptera Phytophaga. Fam. Chrysomelidae. Subfam. Lamprosominae. Bruxelles, Verteneuil \& Desmet, 14p.

BLACKWELDER, R.E. 1946. Checklist of the coleopterous insects of Mexico, Central America, the West Indies, and South America. Bulletin United States Natural Museum, Washington, D.C., 185 (4): 551-763.

Caxambú, M.G. \& L.M. Almeida. 1999. Descrição dos estágios imaturos e redescrição de Lamprosoma azureum Germar (Chrysomelidae, Lamprosomatinae). Revista Brasileira de Zoologia, Curitiba, 16 (Supl. 1): 243-256.

Chapuis, F. 1874. Famille des Phytophages. In: T. Lacordaire \& F. Chapuis (Eds). Genera des Coléoptères ou exposé méthodique et critique de tous les generes proposés jusqu'ici dans cet ordre d'insectes. Roret, Livrarie 
Encyclopédique de Roret, vol. 10, 455p.

Chevrolat, L.A. 1842. In: D'Orbigny. Dictionaire Universel d'Histoire Naturelle. Paris, vol. 2, 796p.

CHÔjô, M.A. 1953. A taxonomic study on the Chrysomelidae from Formosa. VI. Technical Bulletin of Faculty of Agriculture Kagawa University, Kagawa, 4 (3): 237-349.

Costa Lima, A.1955. Insetos do Brasil. 9. Coleópteros. Rio de Janeiro, Escola Nacional de Agricultura, 289p.

Germar, E.F. 1824. Insectorum species novae aut minus cognitae descriptionibus illustratae. Halae, 624p.

Guérin, J. 1953. Coleopteros do Brasil. São Paulo, Faculdade de Filosofia Ciências e Letras da Universidade de São Paulo, 356p.

GuÉRIN-MÉNEVILLE, F.E. 1844. Species et Iconographie générique des Animaux Articulés ou représentation des genres avec leur description et celle de toutes les espèces de cette grande division du Règne animal... I - Coléoptères (paginación independiente). Paris, 576p.

JACoBy, M. 1881. In: F.D. Godman \& O. SAlvin (Eds). Biologia Centrali Americana, Insecta. Coleoptera, Phytophaga (part.) (Sagridae, Crioceridae, Megalopodidae, Clythridae, Cryptocephalinae, Chlamydidae, Lamprosomidae, Eumolpidae,Chrysomelidae, Galerucidae. London, Dulan \& Co., vol. 6, p. 73-144.
1908. Fauna of British India, including Ceylon and Burma. Coleoptera II, p. 281.

Jolivet, P. 1978. Selection trophique chez les Clytrinae, Cryptocephalinae et Chlamisinae (Camptosoma) et les Lamprosomatinae (Cyclica) (Coleoptera, Chrysomelidae). Acta Zoologica et Pathologica Antwerpiensia, Antwerp, 70: 167-200.

KIRBY, W. 1818. A century of Insects, including several new Genera. Transations Linneaen Society of London XII, London, 1-445.

LACORDAire, T. 1848. Monographie des coléoptères subpentamerès de la famille des Phytophages, vol 2. Memoires de la Societé Royale des Sciences de Liège, Liège, 5: 1-890.

Monrós, F. 1947. Descripción de diez nuevas espécies de Lamprosoma neotropicales (Col. Chrysomelidae). Acta Zoologica Lilloana, San Miguel de Tucumán, 5: 81-95.

- 1956. Revisión Genérica de Lamprosominae con descripción de algunos generos y espécies nuevas (Col. Chrysomelidae). Revista Agronomica del Noroeste Argentino, San Miguel de Tucumán, 2: 25-77.

. 1960. Coleopterorum Catalogus. Chrysomelidae: Lamprosomatinae. Suppl. Berlim, Junk, 53 (10): 1-16.

Perty, M. 1832. Delectus animalium articulatorum quae in itinere per Brasiliam colligerunt J.B. de Spix et Th. De Martius. Lipsiae, Fleischer.2: 1-99.

Recebido em 09.I.2003; aceito em 15.V.2003.

Revista Brasileira de Zoologia 20 (2): 329-337, junho 2003 